University of Wollongong

Research Online

Faculty of Education - Papers (Archive) Faculty of Arts, Social Sciences \& Humanities

July 2007

\title{
The Underpinning Knowledge Bases of an Alternative Teacher Education Model
}

J. Kiggins

University of Wollongong, jkiggins@uow.edu.au

Follow this and additional works at: https://ro.uow.edu.au/edupapers

Part of the Education Commons

\section{Recommended Citation}

Kiggins, J.: The Underpinning Knowledge Bases of an Alternative Teacher Education Model 2007. https://ro.uow.edu.au/edupapers/50 


\title{
The Underpinning Knowledge Bases of an Alternative Teacher Education Model
}

\author{
Julie Kiggins \\ University of Wollongong
}

\begin{abstract}
From 1999 the Faculty of Education at the University of Wollongong has run an alternative model of teacher education known as the Knowledge Building Community (KBC) Project. This program has been acclaimed nationally. What makes this program so unique is its design that abandons the traditional model of teacher education that consists of lectures and tutorials; instead this alternative model of teacher education is based on several underpinning pillars of professional knowledge. The KBC program has been described as a "negotiated evaluation of a non-negotiable curriculum based on a constructivist model of learning and knowledge building". However, the basic aim of this program is to deal with the perennial problem of contextualising students' professional learning, by linking abstract theory as closely as possible to the contexts and settings to which it is applied, i.e. the primary school classroom.
\end{abstract}

\section{Introduction}

This paper reports on an alternative model of teacher education that began as a pilot project in March 1999 at the University of Wollongong (UOW) and was known as the Knowledge Building Community (KBC) project. The project started with 22 students from the first year (primary) intake. In the first iteration of the project four local schools were involved. The classroom teachers at these schools acted as professional mentors and educational informants about the culture of their schools for the preservice teachers involved in the KBC project. The Dean of the Faculty of Education, the Training and Development Unit of the New South Wales Department of Education and Training (DET) and the NSW Teachers' Federation all supported the project. Since its inception the KBC program has undergone a series of evaluations and reviews. What the underlying principles and tenets of this program are, that give it the unprecedented success that it has had over the years since its inception will be the focus of this paper.

\section{Background}

University preparation programs for teacher education are many and varied. However, the role of teacher education is to develop and produce effective and competent beginning teachers. What constitutes effective and competent beginning teacher practice, that is, what we expect a beginning teacher to know and be able to do is continually evolving in line with the forever changing climate of schools and communities (Blackwell, Futrell \& Imig, 2003). Much of the literature that is available concerning teacher education suggests that it is a complex process involving a combination of university and practicum experience (Feiman-Nemser \& Buchman, 1985; Britzman, 1986; Goodman,1986; Calderhead, 1991; Groundwater-Smith, 1993; McCormack, 1997; Mayer, 1999). However, some researchers have found that teacher education courses are similar in that they tend to lack an "overall coherence" (Fullan, 1991 p. 291). Added to this criticism is that the purposes of many of the courses and subjects that preservice teachers undertake are complex and hazy (Floden, McDiarmid, \& Werners, 1989; Lanier \& Little, 1986; Kennedy, 1990; MACQT, 1997, CDEST, 
2002; Vinson, 2003 Brouwer \& Korthagen, 2005). Hoban, (2005) says that because teacher education courses often present a fragmented view of learning this can hinder a preservice teacher's development into a flexible, progressive teacher. He claims that there are two reasons for this. He states that many teacher education courses split the study of learning into independent subjects focussing on psychological and sociological aspects which can lead to narrow and fragmented view of learning. He goes onto say that the organisation of these subjects is often based on the delivery of decontextualised, theoretical knowledge that has little relevance to trainee teachers.

We are living in a society that demands that our children are well educated. "A basic education is no longer adequate preparation for life" (Ramsey, 2000, p. 9). In an era when new innovations in teacher education are necessary for classroom preparation it is imperative that preservice teachers be equipped with alternative teaching strategies that challenge the telling and rote learning model (Gunstone, Slattery, Baird \& Northfield 1993; Loughran \& Russell, 1997). In a society that is demanding teaching to be of the highest quality it is imperative that the "systems of teacher education equip teachers with knowledge and skills relevant to the needs of the young people who they are preparing for the transition to work and participation in an ever-changing world" (Ramsey, 2000. p. 9).

Evaluations of preservice teacher education from various stakeholders cast negative assessments on the adequacy of pre-service teacher education. This is confounded by unrealistic expectations that a beginning teacher can fulfil their role as a teacher to the same standard as their more experienced colleagues (Ramsey, 2000). Waldsorf and Lynn (2002) liken such expectation to a first year lawyer being asked to argue a case before the Supreme Court. In research undertaken by Armour and Booth (1999) the theme to emerge showed that preservice teachers were leaving university with feelings of being under-prepared for the transition to life in the classroom. This was reiterated by the schools that employed them when they reported that a majority of graduates were unaware of how school and classroom cultures even operated (Cambourne, 1998). The beginning teachers were unable to see the relationships between what they had studied at university and how it could be translated into classroom practice that produced effective student learning (MACQT, 1998). Armour and Booth (1999) found that most schools who worked with final year primary education students felt that they needed more experience with the day to day operation of schools, and how the daily work of teachers relates to the culture of schools and classrooms. Given that there are a multiplicity of demands that classroom teachers now face teacher education also needs to change and it was in this climate that the $\mathrm{KBC}$ project evolved.

\section{The Purpose of the KBC Project}

As highlighted above the Knowledge Building Community (KBC) project was initiated as a response to research that suggested preservice teachers needed more experience with the day-to-day operation of schools, and how the daily work of teachers related to the culture of schools and classrooms. In his review of teacher education in NSW Ramsey (2000) stated that it was essential for teacher education to undergo such reform. 
Teacher education cannot continue substantially within present models and structures. Reform is needed which reconnects teacher education and schools (Ramsey, 2000. p.50).

The purpose of the KBC Project was to provide an alternative model of teacher education. It was therefore designed to contextualise the delivery of instruction. Since its inception the program's basic aim has been to deal with the perennial problem of contextualising students' professional learning by linking abstract theory as closely as possible to the contexts and settings to which it applied, in this case the primary school and the primary school classroom.

\section{What is a Knowledge-Building Community?}

Hewitt, Brett, Scardamalia, Frecker and Webb, (1995) have said that a Knowledge Building Community (KBC) is a group of individuals dedicated to sharing and advancing the knowledge of the collective. They go onto say that the defining element of a KBC is that its members understand this notion. With shared understanding members will invest in the group or collective pursuit of understanding.

The notion of students and teachers working together in collaboration has been in educational conversation since Dewey but in the last decade has been taking a more definite shape in various programs (Scardamalia \& Bereiter 2000). Scardamalia and Bereiter present the knowledge building community as a means of reforming the culture of the classroom (Hewitt et al, 1995). The adoption of this approach sees the class become a research team aimed at advancing its own "collective, intellectual growth through sustained, collaborative investigations" (Hewitt et al, 1995, p. 1). It was decided that these principles espoused by Scardamalia and Bereiter $(1989,1991,1993,1996,2002)$ would underpin the alternative model of teacher education proposed at the UOW in 1998-9. The student teachers involved in the KBC project at the UOW would therefore learn to work in a learning environment that supported the continuous social construction of knowledge (Vygotsky, 1978).

In order to establish a $\mathrm{KBC}$ in a teacher education setting it was necessary to reposition the delivery of teacher education from a 'campus-based-lecturetutorial' mode to a 'problem-based-learning-within-a-school-site' mode. To achieve this the $\mathrm{KBC}$ project at the UOW was supported by three learning principles.

- Community learning (CL);

- School-based learning (SBL);

- Problem-based learning (PBL)

These three learning principles each carry their own definition specific to the $\mathrm{KBC}$ program at the UOW.

\section{Community Learning:}

Community learning (CL) is a major shift from the traditional teacher education model of lectures and tutorials and this learning principle served to strengthen the working link between the university and the participating local primary schools. It 
required the development of a community of learners, which was made up of preservice teachers, the school-based teachers and the university lecturers who acted as on campus facilitators. This community was designed to establish a sense of trust among all of its members who were dedicated to work together to educate and develop competent emerging professionals.

\section{School-based Learning:}

School-based learning (SBL) was and is the second learning principle of the KBC project. Schools are more than a conglomeration of buildings and people rather they are a set of individual cultures which have evolved in response to the wider cultural values (Bullough, 1987). To function, and indeed survive a beginning teacher must understand this culture. This component of the KBC structure aimed to develop a sophisticated understanding of school-based culture. It is therefore important for preservice teachers to understand how schools do business and how classroom cultures operate and support the learning of all students. It is also necessary as a part of this understanding of classroom culture to know and appreciate how to create and sustain this ethos. The design of this part of the KBC project was and remains a deliberate strategy that aims to reduce the 'reality shock' by increasing the preservice teacher's understanding of a teacher's multiplicity of roles in both the school and the classroom.

\section{Problem-based Learning}

Although problem-based learning has been extensively used in medical and other health professions over the last 40 years it has not widely crossed over into teacher education. It is acknowledged that there are many subjects that use PBL but few teacher education courses that have converted to this mode. Problembased Learning (PBL) theory asserts that PBL encourages and motivates students to 'learn to learn' (Duch, 1995). The critical difference in PBL is that it is characterised by instruction, which involves the students working in small groups to solve 'real world' problems. In this process the students develop skills of negotiation, communication and collaboration (Aldred, Aldred, Walsh \& Dick, 1997). Problem-based learning is believed to promote life-long learning, making knowledge relevant by placing it in context (Aldred et. al., 1997). Above all problem-based learning challenges students to take charge of their education (White, 1996). The common characteristics of PBL are:

- abolishing the traditional lecture-tutorial format;

- changing the lecturer's role from transmitter of facts to facilitator of learning;

- the facilitator will ask open-ended questions, monitor progress, probe and encourage critical reflection, and make suggestions thus helping students to create a positive learning atmosphere.

It was these tenets that the $\mathrm{KBC}$ program adopted together with recognition that in order to do so the students would need an emphasis on team building and team skills. Weekly workshop activities were designed that would provide the students with a greater understanding about how teams worked, the evolution of teams and the role/s each member of a team plays. It was thought that if the students had these skills under control then when they were faced with the normal challenges of a PBL task they would have the necessary and required group cohesion for such an assignment. 
Early research conducted with the KBC students showed that as a group they were extremely empowered as learners. The level of professionalism and enthusiasm demonstrated by the students impressed school-based teacher mentors and university facilitators alike. The KBC students stated that being in an environment where they could voice their opinion meant that they felt valued as a learner. The KBC students identified that what they required as learners was a link between the theoretical and the practical components. However, we recognised that they still needed processes in place that would enable them to take a much greater control of their own learning.

In our early years of the KBC program it was soon evident that PBL as a learning source often proved cumbersome to smooth knowledge building. This was we acknowledged due to the design of the PBL tasks. These tasks proved to be a contributing barrier to the successful implementation of PBL. The majority of faculties that operate PBL provide their students with hypothetical problems that although based on 'real-life' scenarios do not necessarily have to be solved in the real setting. It was our expectation that the KBC students would use the setting of the classroom to work through their PBL task. The constructed PBL problems although based on everyday scenarios of a school or classroom meant that the $\mathrm{KBC}$ students often found that the problem could not be solved in the context where they were situated. Thus the students would force fit their research to fit their learning. This was far from our intention or the ideal for this learning source.

\section{Refashioning PBL for the UOW context}

The KBC model had PBL tasks that were written in an attempt to meet the requirements of the compulsory subjects and were anchored to current school issues but they had not been tested. In fact it was soon obvious that it was the situation that the problems were trying to cover too many curriculum objectives. After the initial enthusiasm of the students had waned the problems no longer motivated the students. Instead the problems had the opposite effect, as the students became increasingly frustrated trying to force fit or resolve them in their various school settings.

The early research cited above was undertaken between 1999 and 2001 and it showed that the attempt to combine PBL in its pure sense as the literature suggested was a bittersweet mixture of success and failure. While working in groups had provided the students with opportunities to experience and develop team and research skills the experience of PBL predominantly provided insights into the pitfalls of trying to implement what might have been called a 'pure' PBL model. The change in delivery from lecture to workshop allowed the $\mathrm{KBC}$ students to develop a strong pedagogical and professional understanding, a view strongly supported by the school-based teacher mentors and the KBC students. This learning was mediated and delivered in a professional context (school) and complemented by collaborative problem solving and community knowledge building in the $\mathrm{KBC}$ homeroom at the university with a facilitator.

Therefore the revisions that the model needed to encapsulate were a contextualising of the university curriculum and de-emphasis of PBL. It was essential to design a model that captured and maintained the knowledge and learning traits of collaborative teams but one that allowed the teams to develop 
their own learning tasks that were specific to their particular school context. The $\mathrm{KBC}$ facilitating team were convinced that this way the students would continue to make connections between theory and practice without the distraction of a contrived PBL problem.

The model that evolved from this revision has become the mainstay of the KBC program and was described by Cambourne (2001) as "a negotiated evaluation of a non negotiable curriculum based on a constructivist model of learning and knowledge building". When one unpacks this over nominalised phrase, it captures what KBC facilitators and students are able to do in the KBC program. The program is delivered along the original guidelines of the $\mathrm{KBC}$ ideals i.e. the three sources of learning. However these three original learning sources are now encompassed into four "pillars' or domains of teacher "knowledge" which researchers and theorists argue are central to the development of effective professionals (Ramsey, 2000).

'The four 'pillars' of the KBC program are:

- Taking responsibility for own learning;

- Learning through professional collaboration;

- Identifying and resolving professional problems; and

- Becoming a reflective practitioner.

These four 'pillars' of the $\mathrm{KBC}$ are a complex set of interactions that are interrelated. When these interactions are working they serve to drive any task that is being investigated. It is timely at this point to fully investigate what activities the students need to undertake in each of these four KBC program 'pillars'.

\section{1. $\quad$ Taking responsibility for own learning:}

Within pillar number one it is expected that the students will:

- Demonstrate that they understand the importance of becoming autonomous, self-directed, independent learners;

- Demonstrate that they knew how to make effective, productive, learning decisions;

- Identify a set of learning "strategies" and/or "tactics" that responsible, selfdirected, independent learners could use and/or draw on; and

- Apply some of these strategies and/tactics to their own learning.

2. Learning through professional collaboration

Pillar number two expects the students to:

- Demonstrate understanding of the value and power of collaborative learning;

- Demonstrate ability to work productively and professionally as a member of a team;

- Demonstrate the ability to deal with inter-group conflict in productive ways.

- Understand how "group dynamics" work and be able to apply principles and "know-how" to maintain group cohesion;

- Demonstrate that they could collaborate in the generation of professional knowledge which all who are members of the KBC community could share and use; 
- Understand the difference between "competitive" and "collaborative" learning and know when either is appropriate;

- Actively support each other's and the whole community's learning; and

- Be honest, "up-front" and professional with each other, especially with respect to opinions and behaviour of others in the community.

\section{Identifying and resolving professional problems}

Pillar number three encompassed the principles of PBL and therefore expects that the students:

- Demonstrate the ability to identify and articulate professional problems, which needed to be addressed and resolved;

- Demonstrate the ability to analyse the key elements in a range of professional problems'

- Make explicit and apply a set of problem-solving strategies and tactics which could be used to address and resolve such problems;

- Demonstrate the ability to identify resources that might be needed to address and resolve a problem, and subsequently find and use such resources; and

- Demonstrate the knowledge and ability to use time effectively in the problemsolving process.

\section{Becoming a reflective practitioner}

The fourth and final pillar of KBC learning engages the students in reflective practice therefore students carry out the following activities:

- Demonstrate the ability to engage in the process(es) inherent in reflective learning;

- Students were expected to make regular, honest, and systematic judgements of the degree to which they believed they had demonstrated the four broad specific outcomes of $\mathrm{KBC}$ in the various learning settings (School, KBC home-room, Self-Directed Learning) by completing self-evaluation reports at regular intervals.

The revision of the KBC model saw the constructed or hypothetical problem synonymous with 'traditional' PBL removed. Problem based learning principles however, remained to guide the students as they designed and negotiated assessment tasks based on the compulsory subjects' outcomes. The KBC students then undertake negotiations with their mentor teacher of the school where they are situated to ensure that the tasks they are planning are appropriate and achievable in their setting.

In the place of the designed PBL tasks are a series of questions that have been designed to guide the students in their quest to master the outcomes of the compulsory subjects in which they are enrolled. This is a four stage approach. At each stage there is a question to guide the students as they work towards designing their own assessment tasks. The questions at each stage are written as a means of ensuring that the students are satisfying the requirements of the compulsory subjects. The four guiding questions are:

- Stage 1 "Let's identify exactly what we are expected to learn in each of these subjects"; 
- Stage 2 "Let's see how we can reduce our workload by integrating and combining what we found out in Stage 1";

- Stage 3 "How can we make best use of our time in school to support what we're expected to learn?" and;

- Stage 4 "What sort of assessment tasks can we design and submit that will convince those who are going to assess us that we have achieved what we're supposed to have achieved?"

The students use the four 'pillars' of KBC learning to support their work through each question at each stage. The principles of PBL are still in use because the students do not attend lectures, and are constantly asking questions and being engaged in problem solving research activities in small teams.

\section{Student insights concerning the Four 'pillars' of KBC Learning}

The observations of the students together with the feedback that they provided are strong indicators that the revised $\mathrm{KBC}$ model allows for independent problem solving, collaboration and reflection. The following KBC students' insights are samples that provided the KBC design team and ultimately the faculty with confidence that the four 'pillars' of KBC know how are effective.

What an exhilarating, fun day I had working within my group. I thoroughly enjoyed myself breaking down the Curriculum and Pedagogy subject. Within this group we are all very much equal with input and this is what made this group's collaboration so enjoyable. The facilitators entered into our discussions and provided some insight and assistance. You learn without realising that you're learning.

Dianne 12/3/05

I think the benefit of the group work is that we are less focussed on the outcome and more focussed on the learning. Therefore gaining real knowledge through action and experience rather than just cramming in the theory in order to move onto the next subject - which we may forget

Linda 15/3/03

I think we've learnt a lot about pillar \#3 of the $\mathrm{KBC}$, "identifying and solving problems", which is really good. The last exercise on the board today was also helpful in making us proactive conflict resolvers. Hopefully we will be able to cool issues before they erupt. The work we did today with the assessment tasks was very worthwhile for me, because I could see the overlapping and underlying themes in all the subject assessment tasks. I thought those to be, understand theory, observe practice and link those together. This exercise has laid out ground rules and a process for when we go into schools. Thanks everyone!

Michelle 4/4/04

The major themes to emerge from the above quotes show that the students realised that learning from each other was a powerful tool. It would appear that the students quoted above had no trouble working under the four 'pillars' and using the four 'stages' as a guide. Michelle spoke about pillar number three encouraging her team to be proactive. Linda stated that the benefit of the group work had enabled learning to occur because the "focus had been removed from the outcome". She went onto to say that they had learnt by doing, and this is of course a primary aim of PBL.

The four pillars of the $\mathrm{KBC}$ are traits that will stand in good stead when the KBC students are beginning teachers. The ability to identify and act on professional 
problems in a collegial manner and then have the ability to reflect upon the course of action taken are qualities that will serve the profession well. Future colleagues and pupils alike will appreciate the benefits of these skills, because the research showed that the KBC students were benefiting by having these pillars underpin their learning.

\section{The KBC 2007}

The journey from project to program, from three learning sources to the four 'pillars' of the KBC has been intense. Yet it has been very rewarding for all the major stakeholders. Since its beginning in 1999 approximately 160 preservice teachers have trusted a new (and for the pioneers in 1999, untried) alternative model of teacher education. One of the most impressive facets to emerge however has been the establishment of a positive working relationship between the university and participating schools (a number that has increased from 4 to 12). Together these stakeholders have been able to overcome some of the documented difficulties associated with the early attempts of establishing an alternative teacher education program based on PBL. However the patience shown on all sides was testament to the results of the students themselves. They were working with difficult problems yet were managing to link abstract theory to classroom practice.

The KBC program is proving itself as a credible alternative to mainstream teacher education a factor that did not go unnoticed by the Carrick Institute for Learning and Teaching in Higher Education, which awarded the KBC program its highest national accolade for a program that promotes innovation in curriculum. Coupled with this was the latest review into teacher education. In February 2007 the review conducted by the House of Representatives Standing Committee on Education and Vocational Training was released. "Top of the Class" was an inquiry into teacher education which confirmed much of what previous reviews of teacher education have said in the past, i.e. that teacher education cannot continue substantially within present models and structures. This latest report said that while not in crisis teacher education needs to do better, (yet another echo from previous reforms). The KBC program at the UOW has shown that it can provide a rejuvenation of teacher education. This paper has shown that although the KBC program has had several internal revisions its basic premise remains intact; that it is a model that has been designed to strengthen the link between theory and practice. However at the same time due its contextual based learning the KBC program is preparing preservice teachers for the demands and rigours of life in the primary school classroom.

\section{References}

Aldred, S. E., Aldred, M. J., Walsh, L. J. \& Dick, B. (1997). The direct and indirect costs of implementing problem-based learning into traditional professional courses within universities. Department of Employment, Education Training and Youth Affairs. Australia.

Armour, L. \& Booth, E. (1999). Analysis of a questionnaire to primary educators at schools accepting students for the six week extended practicum. Report for the Faculty of Education: The University of Wollongong. 
Blackwell, P.J., Futrell, M.H. \& Imig, D.G. (2003). Burnt water paradoxes of schools of education. Phi Delta Kappan, 84(5). 356-361.

Britzman, D. (1986) Cultural myths in the making of a teacher: Biography and social structure in teacher education. Harvard Educational Review. 56 pp 442456.

Brouwer N. \& Korthagen F. (2005). Can teacher education make a difference? American Educational Research Journal 42(1). pp.153-224.

Bullough, R.V. (1987). Accommodation and tension: Teachers, teacher role, and the culture of teaching. In J. Smyth. Educating teachers: Changing the nature of pedagogical knowledge. The Falmer Press. London.

Calderhead, J. (1991). The nature and growth of knowledge in student teaching. Research in Education. 40 pp 33-49. In: R. Dobbins, (1996). Student self esteem in the practicum. Australian Journal of Teacher Education. 21 (2).

Cambourne, B. (1998a). Implementing a problem-based leaning model to a group of primary education students from the 1999 cohort. Unpublished Position Paper. The University of Wollongong.

Cambourne, B. (2001). Personal communication: KBC Planning Meeting, The University of Wollongong: February $12^{\text {th }} 2001$.

Centre for Problem-based Learning. Illinois, Mathematics and Science Academy. (1998). URL: http://www.udel.edu/pbl/others.html

Commonwealth of Australia (2007). Top of the class: Report on the inquiry into teacher education. House of Representatives Publishing Unit.

Commonwealth Department of Education, Science and Training. (2002). An ethic of care: Effective programmes for beginning teachers. Canberra: Commonwealth Department of Education, Science and Training.

Duch, J.B. (1995). What is Problem-Based Learning? The Newsletter for the Centre for Teaching Effectiveness, University of Delaware.

URL: http://www.udel.edu/pbl/cte/jan95-what.html

Feiman-Nemser, S. \& Buchman, M. (1985), Pitfalls of experience in teacher preparation. Teachers College Record, 87, pp 49-65.

Floden, R., McDiarmid, G., \& Werners, N. (1989). What are they trying to do? Perspectives on teacher educators' purposes. In The new meaning of educational change $\left(2^{\text {nd }} E d\right.$.) Cassell Educational Limited. England.

Fullan, M. (1991). The new meaning of educational change $\left(2^{\text {nd }}\right.$ Ed.) Cassell Educational limited. England.

Goodman, J. (1982). Learning to teach: A study of a humanistic approach. Unpublished doctoral dissertation, University of Wisconsin. In K.M. Zeichner, (1983). Alternative Paradigms of Teacher Education. Journal of Teacher Education. 34(3). pp. 3-9.

Groundwater-Smith, S. (1993). The micro-politics of the practicum: A critical issue. Publication of the $5^{\text {th }}$ National Practicum Conference, Learning in the Field: The Current Face of Practical Experience in Professional preparation, Macquarie University, Sydney. In: R. Dobbins, Student self esteem in the practicum. Australian Journal of Teacher Education. 21(2). 1996.

Gunstone, R.F., Slattery, M., Baird, J.R., \& Northfield, J.R. (1993). A case study exploration of development in preservice science teachers. Science Education. 77, (1). pp 47-73.

Hoban, G.F. (Ed.) (2005). The missing links in teacher education design. Springer. The Netherlands. 
Hewitt, J., Brett, C., Scardamalia, M., Frecker, K. \& Webb, J. (1995) Schools for thought: Transforming classrooms into learning communities. Paper Presented at the American Educational Research Association, Annual Conference. San Francisco. URL: http://csile.osie.utoronto.ca/abstracts/kn build/

Kennedy, M.M. (1990). Choosing a goal for professional education. In R. Houston, M. Haberman \& J. Sikula (Eds.), Handbook of research on teacher education (pp. 813-25) Macmillan. New York

Lanier, J., \& Little, J. (1986). Research on teacher education. In M. Wittrock, (Ed.), Handbook of research on teaching (pp 168-191) Macmillan. New York

Loughran, J.J. \& Russell, T.L. (1997). Meeting student teachers on their own terms: Experience precedes understanding. In: J. Brown, B. Doecke \& J. Loughran, Understanding beginning to teach: Learning about the transition from tertiary education to a professional career. Paper presented at the Annual Australian Association for Research in Education Conference, Brisbane

MACQT, (1998). Teacher preparation for student management: Responses and directions. Report by Ministerial Advisory Council on the Quality of Teaching, October 1998. Sydney: NSW Department of Education and Training.

Mayer, D. (1999). Building teaching identities: implications for preservice teacher education. Paper presented at the Annual Australian Association for Research in Education Conference, Melbourne.

McCormack, A. (1997). Impacting on the socialisation of beginning teachers of physical and health education through collaboration. Paper presented at the Annual Australian Association for Research in Education Conference, Brisbane

Ramsey, G. (2000). Quality matters. Revitalising teaching: critical times, critical choices. NSW Department of Education and Training. Sydney.

Scardamalia. M. \& Bereiter, C. (1991). Higher levels of agency for children in knowledge building: A challenge for the design of new knowledge media. The Journal of the Learning Sciences. 1(1). pp. 37-68.

Scardamalia. M. \& Bereiter, C. (1993). Surpassing ourselves: An inquiry into the nature and implications of expertise. Open Court. Chicago.

Scardamalia. M. \& Bereiter, C. (1996). Student communities for the advancement of knowledge. Communications of the ACM. 39(4). pp 36-37.

Scardamalia, M. \& Bereiter, C. (2000). Schools as knowledge building organisations. URL: http://csile.oise.utoronto.ca/abstracts/ciar-understanding.html Stepien, W.J. \& Gallagher, S. (1993). Problem-based learning: As authentic as it gets. Educational Leadership, pp. 25-28. In Exploring the Environment Instructor Notes. NASA. Classroom of the Future, Wheeling Jesuit University. Washington. URL: http://www.cotf.edu/ete

Vinson, T. (2001). Public education inquiry NSW. An inquiry into the provision of education in New South Wales [Online]. Available

URL: http://www.pub-ed-inquiry.org/reports/final-reports/02/FirstReport.html

Vygotsky, L. (1978). Mind in Society: The development of higher psychological processes. Harvard University Press. Cambridge.

White, H. (1996). Dan tries problem-based learning: A case study. URL: http://www.udel.edu/pbl/dancase3.html

Waldsorf, K.L. \& Lynn, S.K. (2002). The early years: Mediating the organisational environment. The Clearing House [Online], 75(4), 190. Available: Electric Library Australasia. 